\title{
Effectiveness Analysis of the Application of Experience-based Teaching Mode to the College Students' Psychological Health Curriculum
}

\author{
Yu Wu ${ }^{1, a, ~}{ }^{,}$, Hong $\mathrm{Li}^{\mathrm{b}}$, Hongjuan Wei ${ }^{1, \mathrm{c}}$, Ameng Zhao ${ }^{2, \mathrm{~d}}$ \\ ${ }^{1}$ Nursing College of Qiqiha'er Medical College \\ ${ }^{2}$ Mental Health Institute of Qiqiha'er Medical College \\ a z1g12@126.com, b824712924qq.com, cjuanzi666888@163.com, d113348606@qq.com
}

Keyword: Psychological health curriculum; Experience-Based teaching; College students; Teaching effects

\begin{abstract}
Experience-based teaching mode is one of the new teaching modes. This teaching mode attaches importance to the students participation and their practical experiences. It is more consistent with the goals of psychological health education, which is aimed to construct the college students' psychological world through the psychological health curriculum in perspectives of improving college students' psychological adjustment ability, promoting their self-growth and increasing the level of self-development. Through experiences and practices, the students are able to achieve self-awareness and sublimation, and then achieve the unity of awareness and emotions, as well as the unity of awareness and actions.

Experience-based teaching mode is one of the new teaching modes. This teaching mode attaches importance to student participation and practical experience, and it is more in line with the goals of psychological health education, which are to use the learned psychological knowledge to guide and solve the problems [1] existing in their daily life and learning process. Psychological health education curriculum is regarded as the main channel to lead students to psychological health learning in most colleges and universities nowadays and play a great role in mental health education in colleges and universities [2]. However, due to the imperfect settings and teaching models of psychological health education currently applied in colleges and universities and the widely used traditional lecturing way that mismatches the actual life of college students and is difficult to effectively mobilize their interests in learning[3-4], most psychological educations fail to achieve the expected teaching goals and do nothing to help the college students with their psychologically growing. Thus, to explore the psychological health teaching mode which is fit for the psychologically growing and improve the psychological ability of the college students should be one of the problems to be solved. College Students' Mental Health Course with the character of instantaneity, with time goes by, we need make a new survey of teaching concept in the new period. It is helpful to grasp the values education aimed at them, and in the establishment of a harmonious society, we must also establish socialist education. The 18th National Congress of the Communist Party of China proposed core value, which also points out the direction for higher education institutions to carry out socialist core values education. College students as the main force of medical and health work in the future, the status of college students' values were the key for China to achieve the service concept of human-centered in the future. Therefore, this study applies this teaching mode to the psychological health curriculum for students in our college to explore its impacts on the learning interests and learning effects for college students.
\end{abstract}

\section{Introduction}

Experience-based teaching takes experience as the center. Teachers create reasonable scenarios in the process of teaching, so as to guide students to build their own knowledge constructions based on their own experiences and personal perceptions through effective teaching methods and means. This mode can well reach the unity of awareness and emotions ${ }^{[1]}$. Value education has a strong social and epochal character. In the current society, people's ideas are updated quickly, and their sense of competition and time are strong. And advocating science and pursuing truth become people's basic behavior or value 
orientation. However, the fast rhythm and strong competition aggravates the physiological burden and psychological problems of human beings. Compared with the previous teaching mode, the experience-based teaching can better promote the active learning of students, and is more in line with the teaching objectives. And compared with the previous text-centered teaching mode, experience-based teaching can better achieve the mutual promotion between teaching and leaning and the two-way transfer of knowledge, which is from teacher to student and then back to teacher again. In western countries, this teaching mode was applied much earlier and has been a relatively mature teaching mode applied to different levels of education and teaching, by which the interactive teaching efficiency has been obviously improved ${ }^{[4]}$. Back to our country, this teaching mode started late of time, thus the application of the teaching mode is still in the exploratory stage. Based on the relevant literature, our college proposed that the teaching mode should be applied to college students mental health education curriculum and mainly plays role in three aspects, which are:

To improve the psychological adjustment ability of college students. The college students psychological health curriculum should not only cover the basic knowledge and skills required for college students, but also should include psychological expertise and skills. A comprehensive psychological health curriculum shall be an organic combination of the above two subjects. As for the teachers, they should find out what to teach. Therefore, it is very necessary to carry on a survey on the students, especially in the freshmen when they entering schools on what kind of psychological knowledge they are interested in. The teacher should choose the contents that students are interested in, and reduce the invalid teaching ones so as to set up reasonable and targeted psychological health education curriculum to improve college students' psychological adjustment ability.

To promote self-growth of college students. During the experience-based teaching, we should not only decide what to teach, but also should know how to teach. in the process of experience-based teaching, the college students should understand and learn about knowledge through personal experience. For this purpose, the teachers need to explain the teaching objectives step by step to make students acquire new knowledge from their personal experiences and practices and realize the processing of the teaching objectives. The knowledge and skills acquired through personal experiences can better promote their self-growth.

To increase the level of self-development of college students. To popularize knowledge of psychological health and improve the psychological health level are the main goals of college students 'psychological health curriculum. As students are undertaking a psychologically sensitive period when they at college, how to guide students to generate proper emotional affiliation and identity is a problem to be solved by college students' psychological health education curriculum ${ }^{[5]}$. It requires the teachers not to rigidly impose the social value system over the students during the course of setting up psychological health curriculum. Instead, they should hold the guiding directions and decide the range of the knowledge to taught through setting situations, so as to enable students to explore their own inner feelings and then enhance the level of self-awareness. The experience-based teaching mode emphasizes the students' experience and acts under the people-oriented teaching philosophy. On the base of fully mobilizing the enthusiasm of students, the experience-based teaching is aimed to achieve self-awareness and sublimation, and then to achieve the unity of awareness and emotions as well as the unity of awareness and actions of students through their own experience and practice, which is also in line with the teaching goal of psychological health curriculum set for college students.

\section{Applicability analysis}

Entering the university, as one of the important turning point in life, may make changes in the environment. The changes in the environment can lead to psychological changes and may further result the psychological crisis, which has been recognized in psychology community. Therefore, for college students, especially the freshmen, college life can be a tough test as they are faced with the conversion of learning styles, changes in relationships and the rich contents of school life which may easily make them under mood swings or psychological distress. Therefore, the teachers should help student to adapt to university life as soon as possible, which is just in line with the intention of experience-based teaching 
mode as it encourage student to explore and complete themselves by experiencing different emotional stimulation.

Creating a situation can help promoting the healthy development of interpersonal relationships among college students

At present, college students are mostly the single children and bear a high expectation from society and family. And the university stage is also a period when they experience the most intense psychological changes and become more sensitive. Therefore, varieties of psychological problems occur to them. As most of the undergraduates, especially the freshmen, have fewer experiences of living with others, they find it is hard to handle the interpersonal relationships under group living. The problems are mainly described as some of them care too much about their own feelings, easily to be self-centered. For a long-term situation, the problems can be described as they feel difficulty in making friends and have a strong sense of loneliness. In our school, a survey concerned with interpersonal relationships was once conducted towards the freshmen. It was founded that about $60 \%-65 \%$ of freshmen were worried about the interpersonal relationships. The experience-based teaching mode shall create situations simulating to their life scene for the purpose of practicing and experiencing interpersonal communications in a safe psychological environment, through experience activities such as "heart of praise", "you say I guess". This kind of teaching shall fundamentally improve their interpersonal communication ability and promote the healthy development on their interpersonal relations.

Group psychology counseling is beneficial for college students to strengthen their sense of belonging

College students' feelings for self-achievement are gradually increasing, which are mainly embodied as the sense of class belonging and the sense of community honor. The cornerstone of the collective construction for college students mainly lies in their sense of class belonging. The differences among college students in personalities are quite large and they are easily influenced by their peers. experience-based teaching mode adopts the group psychological counseling methods,such as quality development and brainstorming, to strengthen their sense of class belonging and make them understand the relationship between individuals and groups by their own experiences, which will help increase the cohesion of the community, as well as establish the sense of community trust and enhance their sense of belonging from their bottom of hearts.

experience-based teaching mode is conducive to self-exploration and improvement of college students

College students, who are deemed to be favorites, tend to have a strong sense of superiority. When entering college and faced with colorful college life and interesting community activities, they mostly choose to participate in various activities, ignoring the learning. From a psychological point of view, the positive experience will promote the internal driving force and transfer the students' attention, thus reducing the impact of psychological anxiety and other discomforts on college students. Therefore, the experience-based teaching mode is the method to promote students to continually correct self-understanding through all sort of positive experiential activities and then accomplish their self-exploration,perfection, and the harmony of both bodies and minds.

\section{Experience-based teaching mode is introduced into the curriculum of college students psychological health}

According to the psychological characteristics of freshmen in aspects of study and life, the author applied the experience-based teaching mode to the psychological health curriculum of the freshmen in 2016. During the teaching practice, the author organized related teachers to collect and classify the psychological topics current college students are interested or concerned in by means of questionnaire survey and then these topics were selected and determined by the psychology professional teachers of our school, to determine 9 psychological topics as the teaching content and to adjust the teaching mode to a combination teaching mode of "theory plus experience", in which the theory teaching adopted the form of classroom lectures, while the experience teaching was changed to small-class teaching mode. The teaching mode mainly adopted the participatory and interactive term and the "psychological growth 
diary" to record and reflect on their own psychological growth were added as one portion of the the final exams. The curriculum setting and teaching objectives of experience-based teaching mode mainly cover the following three aspects, through which to build a teaching mode suitable for the teaching purposes, contents, means, the psychological status of students and the teaching atmosphere.

To set goals and start the experience. It is a new teaching mode in the psychological health education curriculum to teach and lean under the real situation and put importance on the interpersonal emotional communication in the group. Based on the learning mode of "initiative, cooperation and inquiry" advocated by the Ministry of Education and in the setting of experience-based teaching mode, it is encouraged to carry out group counseling, quality development, movie viewing, case analysis and other visiting experience according to the psychological characteristics and development needs of college students at different stages ${ }^{[6]}$. Before starting this study, the author conducted a survey on psychological counseling and other information among freshmen in 2013 in our school. About $95 \%$ of the students had a basic understanding of the functional orientation and secrecy of psychological counseling; $84 \%$ of students made it clear that if there was any psychological problems or discomfort, they would seek for psychological counseling. After being applied to experience-based teaching, students of 2013 received another survey. It was found that the numbers of students who accepted counseling students has risen to $96 \%$, compared with $84 \%$ at the enrollment.

It can be seen that experience-based teaching, as a carrier of popularizing education of mental health, can create a chance to achieve self-exploration and perfection for college students by creating a scenario under psychological safety. Based on the teaching content of experience-based teaching mode, students can take the initiative to learn and construct the correct values, to realize the positive energy from their minds, and to cultivate their sound psychological quality, so as to obtain enlightenment and sublimation, which is also the goal of psychological education.

\section{Immerse in the experience and feel the heart}

It has been shown that emotions and feelings affect the way and method of cognitive activity. In the process of experience-based teaching, comprehensions are generated from the interaction of students, knowledge and scenes. When apply this teaching mode, we should take the students as the main factor and respect their different needs, motivation and care every single individual ${ }^{[7]}$ to promote college students' self-understandings and feelings, so as to achieve the teaching goal. In the process of setting the situation, teachers should guide the students to experience correct and truly integrate themselves into the context, finally to achieve empathy. At the same time, it should be noted that in the process of teaching the teachers should pay attention to the psychological state of college students and timely record of how they experience the settings, providing materials for further exchanging and sharing. These studies analyze and grasp values and related issues were mainly from the macro perspective. As for the specific studies of a special group were rarely, such as young people's values education problems.

In the course of my psychological health education, I set a section on "Wills in Life" enabling students to integrate into this situations, to analyze their own situations and to find out their shortcomings through analyzing situations related to their life and family. In this section, $62 \%$ of participating students said that for the first time, they reviewed the course of their past lives, which made them begin to re-recognized their parents and their families and cherish their families and the time right in front of them more than before. It is obvious that through the experience-based teaching mode of "situation - experience comprehension", students are fully released their psychological ability and able to learn and comprehend in conflict and joy. It enlighten them to experience themselves more deeply and be considerate of others, and finally develop and perfect themselves in the direction of "help yourself before you are able to give help".

Focus on sharing and multiple interaction. In the experience-based teaching mode, teaching point should be focused on the interactive sharing. For the teachers, teaching should be guiding students to understand the process of knowledge generation instead of simply being a infusion of knowledge. The teacher should grasp the key points of the experience-based teaching mode and value the process of discussion and concept exchanging. Therefore, in the process of teaching, we should attach importance to multiple directional interaction according to the syllabus, design guiding questions among groups and 
classes, help students share their psychological confusions, and give them in time advice and guidance to build a democratic and harmonious teacher-student relationship and encourage students to achieve self exploration and development.

In conclusion, previous mental health courses are mostly focused on the theory education and neglect the teaching methods and contents to improve the psychological quality of students. From the point of the college students, the fundamental purpose of psychological health education is to improve their overall psychological quality to handle with the tress and frustration ${ }^{[6]}$. The experience-based teaching mode is trying to introduce the students to the experiences of bad emotions, stress and frustration through the melodrama, interactive discussions and other hypothetical scenarios so as to build the correct mental health knowledge and perception. Compared with the previous psychological health education, the experience-based teaching mode is more in line with the purpose of the psychological health education curriculum ${ }^{[7]}$. The reason may be that the experience-based teaching mode are rather reasonable in terms of contents and methods, which tend to facilitate the construction of a positive curriculum. This teaching mode emphasizes self-experiences in all kinds of activities, and attache importance to the process of students' development. The activities designed for students not only include melodrama, but also cover movie appreciation, which would increase the chances of communication among the team members, as well as enhance their psychological experience. These communications and experiences can help them get a profound understanding of themselves and others and promote self-reflection and understanding ${ }^{[8]}$. Furthermore, the real social situations arranged in the experience-based teaching mode can better promote the study and practice of students. In addition, it is necessary to emphasize that the premise of a successful experience-based teaching mode should be a reasonable lesson plan design. The lesson plans in this study, which are designed and confirmed by the professional psychology teachers in our school after careful discussion totally based on the previously collected topics that current college students are interested and concerned in, strives to be interesting, targeted and practical as well. The lesson plans can make student devote themselves into the designed situations under the acceptable classroom atmosphere, thus better opening up the minds and releasing the emotions to get mental growth.

The value education of contemporary Chinese college students is faced with such a new environment full of new situations, new contradictions and new problems. It is effective and necessary to study the core values of college students in the new period, for understanding the current situation and problems of College Students' values, and guiding students to establish the correct values. The experience-based teaching mode is good at dissolving mental health knowledge into teaching methods such as emotional experience education and behavioral training, which not only enables them to acquire knowledge, but also makes them pay more attention to their emotions and behaviors so as to unify the three aspects of knowledge, emotion and behavior. Compared with the previous teaching modes that neglect the students' experience while emphasize the theory lecturing, the experience-based teaching mode can better make students can get the empathy ${ }^{[9]}$. In the past teaching practice most of the students were passively learning the knowledge, while in the experience-based teaching mode students are active participants, even organizers, who can actively construct their own knowledge. Studies have confirmed that $10 \%$ can be learned through reading the whole information but $80 \%$ can be learned through experience it ${ }^{[10]}$. It is revealed that the first-hand knowledge and insights acquired by experience are more profound and unforgettable, just as and old Chinese saying "the knowledge acquired through reading is far from enough. practices makes a master." At the same time, in the process of previously teaching, the communication between teachers and students is one-way, simply from teachers to students. However, the experience-based teaching is two-way, or even multiple directional. Through the communication between teachers and students and communications among students, students can obtain rich experiences, to achieve the unity of "knowledge and skills, processes and methods, emotional attitudes and values ${ }^{[11]}$.

\section{Acknowledgment}

This work was supported by Social Science Foundation of Qiqihar Medical College, the project number QYSKL2015-17. 


\section{References}

[1] Liu Xiaoqing, Jiang Changxiang. The Application of experience-based teaching in College Students' Mental Health Curriculum - A Case Study of the Freshmen Psychological Counseling Course[J] Education Theory and Practice, 2012,30 (10): 62-64

[2] Chu Yongjuan. The application of experience-based teaching mode in College Japanese teaching [J]. Education Exploration, 2012,26 (1): 29-31.

[3] QIU Xiaoyan, SONG Hongfu.Experimental Research on experience-based teaching of College Students' Mental Health Education Curriculum [J]. Journal of Educational Sciences of Hunan Normal University, 2013,12 (1): 95-98

[4] GUO Junru, FAN Chengbo. Research on the Application of experience-based teaching in mental health courses in independent colleges [J]. Journal of Jiamusi Education Institute, 2014, (3): 290-292.

[5] Ministry of Education Chinese College Students Mental Health Assessment System Research Group. Chinese College Students Mental Health Scale (CCSMHS), China College Students Mental Health Assessment System Scale Manual [R] .2005,6.

[6] WANG Yuhua.Comparison and Analysis of Effectiveness of Different Mental Health Education and Teaching Methods in Colleges and Universities [J]. Chinese School Health, 2014,35 (6): 832-833

[7] WANG Jingyun. Application of experience-based teaching in College Students' Mental Health Education Curriculum [J]. Journal of Heihe University, 2016, (2): 62-64

[8] Gao Fei. Commenting on experience-based teaching in Psychological Health Education Curriculum in Colleges and Universities [J]. Journal of Southwest Jiaotong University (Social Sciences Version), 2013,14 (1): 91-95

[9] BI Aihong, YANG Weihua, YUAN Linjun. Exploration of Experiential Education in College Students' Mental Health Education [J]. Party Construction in School and Thoughts Education, 2010, (7): 65-66.

[10] Yin Xingyan. An Empirical Study on the Effectiveness of Experience-based Teaching Method in College Psychology Lesson [J]. Education and Careers, 20 10, (14): 153-154.

[11] Ni Haizhen. Application of experience-based teaching in Psychological Health Education for College Students [J]. Journal of Luzhou Vocational and Technical College, 2010, (4): 135-136. 